\title{
"Esculacho" and other spoken meanings of pacification in Rio de Janeiro
}

Alba Zaluar

Anthropology has given us quite a few vital lessons. First, that the native always has the last word, but that there are several natives. Second, that society is a web of more or less systematic relationships with more or less defined boundaries. Third, that culture is a grid of fluid and crystallized meanings, integrated or not into a system, having just some autonomy vis-à-vis other cultures, which some authors claim to be irreducible. Fourth, not always accepted or conveyed, that changing processes are inevitable, even in the most stable societies and more crystallized cultures, and thus it is necessary to extend the analysis as far as possible, in the twofold sense of space and time, in order to understand how plots, dramas, and networks interconnect and develop.

The problem is that even only somewhat integrated and stable "cultures" or "societies" are increasingly difficult to find in today's globalized world. Undefined borders, fluid cultures, soft societies, hybridity, syncretism and creolization (Stewart \& Shaw, 1994; Clifford, 1988) are the new issues that curse the reflection of those who saw their own and other societies with enviable clarity, within which groups and categories had clear and unambiguous identities.

Therefore, I believe I was right when I mentioned the need to understand the violence currently manifested in Brazil not only as a geological effect of cultural layers of customary violence since the colonial period, but also as part of the transnational crime setting that stemmed from the process of globalization with sui generis economic, 
political, and cultural characteristics that allowed a marginal or illegal business activity to thrive, without ceasing to be a capitalist enterprise with unrestrained pursuit of profit (Zaluar, 2004). Based on this fact, it is impossible to deny the need of extending the analysis further in order to include business crime networks across national borders, i.e., beyond the webs that link those who choose to live not always as outlaws, but as part of a peculiar mixture of legal and illegal businesses. The image of a boy from a slum holding a AR15 or UZI machine gun in his hand, which he considers symbols of his virility and a source of power and social prestige, wearing a cap inspired by the black movement in USA, listening to funk music, sniffing cocaine produced in Colombia, longing for the latest model of Nike shoes and a car of the year, all of which he becomes ready to kill or be killed for, cannot be explained, to say the least, only by the level of the minimum wage or the unemployment rate among young slum dwellers, or even less by backland customary violence. Understanding who delivered to him these instruments of power and pleasure on the one hand, and who taught him the values that drove him to the pursuit of pleasure and power on the other hand, are obviously issues independent of the local minimum wage (Zaluar, 2007) and the customary violence, both of which nonetheless contribute to his vulnerability and subjective formation.

Therefore, I followed some theoretical assumptions:

- One cannot treat the favela as an entity or a homogeneous, consensual and unified community. Indeed, on the contrary, there is a great diversity that segments the population according to gender, age, religion, income, education, profession, occupational position, and even social origin. Favela dwellers are largely migrants from other cities and states intermixed with local people - mainly with blacks who have been living in favelas for more than one century. 
- The Anthropology of everyday life can no longer naively take for granted that individual or collective meanings are spontaneous, autonomous, with clear marks of popular ideology and class interests without passing through the filter of interactions with other political actors, including political parties and social movements, as well as the media and other cultural industry agents. Many actors are interacting and influencing each other in intricate processes of interpretation, engagement, and ideas or values that require renegotiations of institutions, practices, and public policies.

- The Anthropology of the state or the margins of the state (Das \& Poole, 2004) cannot be based on dichotomies that consider those from the poorest sectors, who live with precarious employment opportunities, low-quality public services, and vulnerability to risks (health, work, security), as if they were all equally submitted to the lies of governments and ignorant of the laws and the state's logic. There are several levels of knowledge as outcomes of different forms and levels of education, age, sociability networks, and political connections, as well as the discussion of binding laws and functions of state agents near them, including policemen. Various social movements may arise from this knowledge. Furthermore, one cannot consider miscellaneous groupings of favela dwellers, some of them migrants from several areas of urban Brazil but all of them legal citizens of the country, as if they were foreign immigrants or tribal forest people, or holders of a traditional non-occidental culture that one must consider in its absolute otherness. Nor are they completely excluded, since they can at least vote in municipal, state and federal elections, and have access to state schools as well as the state universal health system (SUS) or several distributive programs, like Bolsa Familia, Minha Casa Minha Vida etc.

- As a more careful approach, I want to avoid the pitfalls of a new trend in studies of violence in Latin America that questions state legitimacy and denounces state 
violence through the embodiment of violence by terror or fear, without considering the effects of non-state or transnational armed criminal organizations that use terror or fear over unarmed people because of fragile and ambivalent institutional control. The idea of a "culture of terror", a "culture of fear" or a "culture of death" is not only a sweeping generalization, but also a theoretical construction that implies that the body incorporates this culture so that one can read it from the effects it has on the bodies on which state violence is written. Then it becomes the ever-present space of death where "death has no end" (Taussig 1987, 382). The idea behind such terms is that violence is intended to create terror and consequently political inertia and silence among the poor, who are exploited, oppressed and violated people, ultimately suggesting that what is at stake is their bodies and not their mind, which are the mediators between their bodies and the outside world, where they feel and think. Nonetheless, for sociological reasoning, it is not the sweat, so cited by those who uphold the affect perspective, that matters for it is just a sign of emotion, a bodily reaction to fear linked to threats. What matters is how people understand and give meaning to their own sweat and other people's sweat as signs of several nuances of fear that only humans are capable of, and how they deal with these elaborate feelings somewhat unconsciously, somewhat consciously (Turner, 2000). Favela dwellers do not lose their thinking and acting capacities.

- Today, we have additional problems in avoiding the traps in which those trying to understand what goes on during the setup of public policies that affect various social agents through mass-media information. One must also avoid the arrogance of treating favela dwellers as alienated, deceived or "cultural idiots" produced by the media that in its turn is presented as a homogeneous and unison block that always fools the people. This dichotomy arises from others: rulers $X$ dominated; included $X$ excluded; white $X$ black; state X social movement; Police $\mathrm{X}$ slum dwellers, each presented with a heavy 
load of moralistic judgments coming very close to Manichaeism, that is, of goodness versus absolute evil.

- Reflexivity, an approach used by anthropologists before its more recent use by sociologists concerned with global issues, is not unidirectional. On the contrary, it is also plural, for the groupings or networks involved are various and not at all homogeneous. As it depends on interaction with social agents who are on the ground, and on groups whose conflicts and problems one tries to understand, one must admit that today they are far from being similar and univocal. Since we started the research in favelas with UPPs, I noticed that the speech of many community leaders repeated expressions and ideas of broader political groups outside the "communities" for which the speech was directed. So what can be considered as the "culture" of the favela dwellers? How are they linked to broader social movements, parties, and political leaders?

Within and between slums, diversity is great. The areas with higher relative and absolute deprivation increase geographical mobility and contain a somewhat heterogeneous population, with adolescent and single mothers, youngsters outside school and work, traffic and militia factions, which in turn loosens social ties, decreasing neighborhood associations and informal social control. ${ }^{1}$ To the personal characteristics, as measured by census data, ecological variables should be added: the social bonds of trust between neighbors, the homogeneity of moral values, and institutional resources. For Sampson et al. (2002), several interconnected mechanisms explain the striking differences found between neighborhoods in the USA. First, the connection between concentrated disadvantage and the geographical isolation of African-Americans, or racial segregation as a neighborhood variable that causes the concentration of several

\footnotetext{
${ }^{1}$ Women migrated to Rio de Janeiro to find better jobs, but also because they were expelled from home by their parents after loosing virginity or being pregnant outside marriage. This traditional culture of the Brazilian backlands was also much weakened in the city.
} 
social problems, such as social and physical disorder, and individual variables, such as low birth weight birth, infant mortality, school dropout, and child abuse, all of them linked also to family variables, for example households headed by women. The authors explicitly recognize that social capital theory contributed to understanding the mechanisms that were measured in different studies by the density of social ties between neighbors, the frequency of social interaction among neighbors, and the standards that make up neighboring and collective efficacy. These mechanisms, which refer to the willingness of neighbors to intervene protecting youths, is also dependent on the trust built between them. In Brazil, the concentration of these problems does not occur in the same way, nor is linked to racial segregation, as the favela population is mixed. In Rio de Janeiro, a similar study ended up with a paradox: precisely in Rio's suburbs, where we find that historically and statistically there is more interaction, more associations, and more trust between neighbors, violence measured by the homicide rate is the highest in the city (Zaluar \& Ribeiro, 2009).

A third line of reflection points to the mechanism of institutional resources that include schools, libraries, centers for recreational activities, health centers, parent support and youth agencies, employment opportunities - factors that interest us greatly because they reveal the differences between Brazilian cities and those of other countries. The number of organizations in the vicinity and the participation of neighbors in these organizations constitute the measurement of this mechanism, according to the same authors. Thus, collective efficacy is linked to what Putnam (2006) called civic participation, clearly concurrent to public order and its institutions, still largely absent in government organizations that provide public services in poor neighborhoods in Brazil. 
Though not agreeing with the idea of a homogenous and "affected" silent margin, I agree that the poorer and marginalized population is the main focus of the system of justice in Brazil, which only now is shifting towards judicial actions against powerful businessmen and politicians. Even so, as always happens when prejudice and stereotypes of criminals predominate in the imaginary of policemen, there is a certain inertia in the investigation of covert networks for trafficking illegal drugs and weapons, besides many other mafias that control illegal businesses, even when the goods or services are legal, like real state business, alternative transportation, cable TV. These articulated networks go beyond barriers of class, urban perimeters, state and national borders, and encroach in legal business, in state institutions, and in governments. Since scholars and journalists sometimes point out the relationship between state officials and drug traffickers, one knows that a vast network goes upwards. But the more visible part, that is, the retail commerce done by the most humble of organized crime members located inside favelas - the "bocas-de-fumo", has always been the preferential object of violent police operations called "blitz" that were common before 2008.

There remains, thus, the difficulty of knowing the great banditry in Brazil since the large bandits were, till recently, not investigated, nor tried, nor sentenced with the same effort put on the bad guys of lesser caliber, that is the retail drug dealers. Police investigation about the activities of the latter is still marked by repression and by various manifestations of ingrained prejudices against certain categories of people, such as favelados, blacks, and poor youngsters, despite recent and important changes in public security policy. Not surprisingly, there is a lack of information for reconstituting the dynamics and flows of various types of organized crime, including the traffic of illegal drugs and guns that attracts vulnerable young people in deprived areas of the country. 
And favelados know it and are outspoken about it, reaffirming that "the policemen themselves bring the guns to the traffickers".

Therefore, some of these youths were prepared to cooperate with drug dealers from childhood. Children grew up in areas where the latter walked with their guns, gave orders, paid lavishly for fiestas and were talked about. The stories about their deeds were an important part of the people's talks in the neighbourhood. Children were thus enticed to the drug dealers' gang as long as the samba and football idols lost ascendancy over youths. They approached the latter not by carrying guns, but by going to buy food or carrying things between the dealers who were in different parts of the neighbourhood. They entered the gang later on, when they were able to show "disposition", that is, mugging or killing someone with the gangs' small guns. They gained status (or respect or consideration) the more guns they brought to the crew and the more enemies they killed, herein included policemen. Killing a cop gave them lots of prestige inside the crew. Therefore, there was a kind of socialization in the streets necessary to be accepted and respected inside the hierarchical system of power and prestige. These crime organizations could thus be considered a field of force with its own rules for establishing hierarchies between its members. The ethos or habitus was acquired since childhood by the example and fame of elder traffickers, and the illusion proper to the tacit rules and practices that they learn early and informally. Nevertheless, this illusion did not blind all of them, altogether, and all the time.

At late 1980, traffickers were organized in three rival criminal factions that contested the territorial control of favelas, when a permanent war between them, supported by a systemic form of corruption of policemen, started. Then the "donos da boca" (owners of the selling points) joined the factions, armed all gang members as if 
they were in a gun race or a kind of "cold war" to deter their enemies, and became the "donos do morro" (owners of the favela or hill).

The homicide and other violent crime rates soared in the city and the traffickers' factions obtained the territory control of most favelas in Rio de Janeiro (Zaluar, 2004, 2007). In order to gain state control over these favelas and reestablish the rule of law, a new security policy was developed in the city that grew out of many power disputes and different conceptions of policing and crime fighting. There were many challenges and risks in different spheres.

This new public security policy, based on the occupation of favelas by Pacification Police Units (UPPs), finally started in 2008 and enabled various alliances and strategies between security officials and residents of pacified favelas. Although old tensions and secular mistrust between policemen and dwellers have not disappeared, this new policy was received well by most city dwellers inside and outside of favelas. Recently, new clashes between them reappeared, often resulting from conflicting interests or the police's arbitrary acts, such as truculence and corruption still employed despite the project of pacification based on proximity to the residents. The complexity of this new kind of policing is also the result of maintaining two very different policies. One policy perpetuates the prerogative of law enforcement through the use of legal but not legitimate violence, such as checks inside homes of favela dwellers, searches inside their bags and backpacks. The other policy aims to community policing, that is, mediating conflicts, giving guidance and information about civil documents, receiving residents' complaints and requests about public services. Initially, as a way of making connections between them, policemen even participated in the residents' sportive and cultural activities, such as playing soccer and the guitar with youths. Soon, as former local leaders, organizations, and long-standing neighborhood associations objected to 
this invasion of their functions, this tactic for gaining acceptance and sympathy was forsaken. Nevertheless, policemen working in UPPs have a dual function: on one hand, seizures of drugs, weapons, and arrests of persons; on other hand, supporting or helping dwellers with various problems.

According to the UPP RJ site, the situation in August 2014 was the following: 38 UPPs installed in complex of favelas since 2008, fetching 1.5 million people in 221 favela units that were occupied by permanent police forces engaging 9,543 policemen with a short training as proximity police in $9,446,047 \mathrm{~m}^{2}$ of occupied area. Numbers show that the program progressed but say nothing about the problems, dilemmas, and challenges that policemen confront during the occupation for building up relations of trust and proximity with dwellers.

First, one should examine the consolidated statistical data that exhibits the relative benefits of this new policy. Official data on deaths by intentional aggression (as collected from death certificates at DATASUS) published in the site Rio Como Vamos, reveal a striking decrease in the juvenile deaths by aggression rate at the Administrative Region of the Alemão Complex: $85 / 100,000$ in 2009; $79.92 / 100,000$ in 2010; and 47.69/100,000 in 2011. All over the city, this source of data shows an equal drop: 115.81 in 2009; 100.26 in 2010; and 63.74 in 2011. The local newspaper "O Globo" disclosed in March $24^{\text {th }}$ of 2013 that there was also a spectacular fall in the amount of police gun fire: there were 40,332 shots fired in $2007 ; 53,657$ in $2008 ; 28,484$ in 2009; 23,334 in 2010; 4,244 in 2011; and "only" 2,395 in 2012. The number is still excessive but it is more than 20 times smaller than in 2008, when the first UPP was established at Santa Marta favela.

Other studies point to the same tendency in the city. Zaluar and Monteiro (2012) showed a decrease of $40 \%$ in the mortality of people with 15 to 30 years of age that lived 
in the poorest Administrative Regions. Data from $\mathrm{CESEC}^{2}$ confirms the fall of the homicide rate in Rio de Janeiro (capital and state): at the capital, 45.7/100,000 in 2002 for 22.4/100,000 in 2011, whereas, in the state, it varied from 46.6/100,000 in 2002 to 26.3/100,000 in 2011. Although still considered excessive according to the World Health Organization (WHO) standards that established a 10/ 100,000 rate as acceptable, data showed a decrease of around half in the city and the state of Rio de Janeiro.

More recent studies done at the Laboratório de Análises da Violência of UERJ, using another official source of data - homicides (registered as police incident report at ISP) -- during 2012 and 2013, show that homicides in 30 UPP areas decreased even more than in the rest of the city and state. In these areas the rates dropped $26.5 \%$ between 2012 and 2013 (49 people murdered in "pacified" areas in 2012 and 36 in 2013), a tendency opposite to the one registered in the city where the rate grew 9.7\% (from 1,206 cases in 2012 to 1,323 in 2013), that is, homicides diminished more inside favelas occupied by UPP than in the whole city. Deaths due to confrontation with policemen also declined from 19 in 2012 to 12 in 2013. Recent research therefore indicates a reduction in the murder rate, but the number is still high considering the expected impact of the pacification policy. Journalists and researchers of a NGO calculated that 7348 lives were saved between 2007 and 2013 in the state of Rio de Janeiro, considering the rate prevalent in 2007 and projecting it to 2013. Lives may have been saved but the number of murders is still far from acceptable. The present proportion of 28 homicides for 100,000 inhabitants is still almost three times greater than the one recommended by the WHO. During the first 55 days of 2014, at least 45 people were killed in police operations inside some favelas of Rio de Janeiro.

2 Available at: http://www.ucamcesec.com.br/wordpress/wp-content/uploads/2011/04/Homic1991_2011.jpg. Accessed in 24/02/2013.

RRASILIANA- Journal for Brazilian Studies. Vol. 4, n.2 (2016). ISSN 2245-4373. 
These modest results may be explained by the pre-electoral political context, that is, of an ending government, and by the protests against international events that happened in the city in 2014 (World Cup) and will take place in 2016 (Olympic Games). But one should also examine the challenges for the UPP occupation, the first of which is the public security institutional engineering, in which the aspects presented by experts as obstacles for a good running little has changed:

I. The segregation between the police, the judicial, and the criminal enforcement systems, besides internal divisions in each of them, makes communication and cooperation among their several structures and corporations more difficult, provoking in its turn useless conflicts and rivalry between the public agents that still tend to act apart from each other;

II. The strategy of war against bandits and the war on drugs lingers as proximity policing is implemented because there was no change in the legislation and public policy related to the drugs defined as illegal. These are still demanded as source of pleasure by several sectors of the Brazilian population and are still sold and bought. The so-called militarization of the security policy is resultant more from the idea of a war against drugs and the hunt of traffickers than from the name "military" carried by one of the four police corporations existing in the country.

III.The slight change in the Brazilian system of justice renews the preferential punishment of poorer criminals and the surveillance of the poorer, less educated and more unemployed population, especially those who inhabit the areas with worse public services.

IV.A lack of a professional ethos still orients military policemen in their actions as enforcers of the law within public space. 
$\mathrm{V}$. The reactive actions based on repression of the dispossessed still prevails over of investigation based on new technology and bureaucratic rationality with basic and clear principles, norms, and rules for all agents, that should also be known to those who are the object of police action.

VI.The insufficient planning of new strategies, adopted to lessen former problems, and no discussion of new problems, such as post-traumatic stress, continues. The stress affects policemen after the deaths of colleagues as a result of traffickers' shootings at the surveillance post or during battles with them. Today, daily or hourly provocations and death threats are addressed to them at favelas that were the most important emporiums of drugs and guns, such as the Complexes of Rocinha and Alemão.

In the complex of favelas called Alemão near the city's port and international airport, because armed forces occupation in 2010 ended the traffickers' armed domain without arresting the majority of local drug dealers, only pushing the traffickers with police records towards other regions of the city, younger dealers with no criminal record and with less gang prestige continued to live and work discreetly there. These younger drug dealers could not show off guns and had to keep themselves in small alleys of the favela. Still, reports of clashes with policemen, armed disputes over the control of selling points (boca de fumo) and even territory, orders for local shopkeepers to close down their shops, recently became more and more common. These clashes could, in general, be considered a return to the initial model of illegal drug trafficking as it was practiced since the 1970s.

Such reappearance of a prior model struck forcefully the traffickers who joined the factions and their practices of systematic corruption of policemen and permanent war with enemies. During a few decades of enduring turf war, they also developed a 
masculinity style based on the visible use of automatic and semi-automatic weapons, luxurious cars, modern motorcycles, and golden jewelry inside the favelas they dominated (Zaluar, 2004). These were the wealth symbols characteristic of hypermasculinity that assured them social prestige and power. Therefore, the armed control of entire favelas was not restricted to the use of guns but also on their display, along with conspicuous consumption practices that guaranteed territorial domination as well as the attraction of women and new soldiers for their gangs. After the UPP occupation, drug dealers complained mostly about losing prestige and not being able to exhibit their power as they used to, including the parties and funk balls they gave to impress the dwellers and sell drugs.

Hence, the occupation of several favelas, especially of the Alemão complex located near the port and the international airport of Rio de Janeiro, generated tensions between traffickers, policemen and favela dwellers. Some traffickers interviewed ${ }^{3}$ stated they felt diminished and humiliated by the police presence where they used to thrive. Commercially, they were confined to the alley where they had to conform to selling drugs quietly and "peacefully". Socially, in the local social networks, they were losing the power to attract the girls and impress the boys who admired them so much beforehand. Worst of all, some women started, without fear of being killed, to be lured by policemen who worked there every day. And the boys, that had to be replaced because of the high mortality rate resulting from clashes with enemy factions and with repressive or corrupt policemen, could become more difficult to find.

The contingent of 9,349 new policemen employed in the UPPs till July 2014, who received a six-month training in proximity policing, grew too quickly during the past 5 years. After 2013, youngsters from the inland were thus prepared to work in the capital

\footnotetext{
${ }^{3}$ The NUPEVI researchers Rodrigo de Araújo Monteiro and Ana Cristina did the interviews.
} 
of the state of Rio de Janeiro, where favelas, though occupied by the Military Police, still sustained drug dealing. At the same time, drug dealers started to walk again with guns in their hands or waists, engaging in gunfire with other dealers or policemen, mainly inside the most lucrative favelas for drug dealing.

Exactly at this time, several strikes and daily demonstrations began to be tailed with riots initiated by black blocs that hit public premises, vehicles (mainly buses), bus stops, newsstands and electronic banking terminals. To confront demonstrators, repressing them as usually done by the Military Police and its Special Operations Battalion (BOPE), famous for its abusive use of force, many of these new recruits, who received a short training in how to deal with residents by dialogue and respect, were engaged at this new front. They had to learn quickly the old methods of repression and abusive use of force at the scene. The logic of action that prevails in policemen' organizational ethos became even more evident in the increasingly tense situation that developed in the city and its occupied favelas, which lost some policemen. Drug dealers smartly began to exhibit guns and drugs sold openly without hiding in the alleys where they stayed during the past years. According to the dispute system involving three factions in Rio de Janeiro, the sale outlets that showed weakness became the target of enemy factions. The favelas occupied by UPP were again in this game for drug dealers had to display powerful weapons and enlist new soldiers, essential in the deterrent strategy adopted to frighten enemies. Gunfire between them restarted, making mandatory the visible and constant use of firearms. Confrontations between policemen and drug dealers restarted as well, with it the "hunt to bandits" former strategy that includes torture and bribes sometime. At this very moment there is a struggle inside the Military Police to establish which modus operandi will prevail.

3RASILIANA- Journal for Brazilian Studies. Vol. 4, n.2 (2016). ISSN 2245-4373. 
After the 2013 protests, one dweller of the most important favela in the richest part of the city - Rocinha - was tortured and killed by policemen in the UPP led by a former official of the most repressive battalion of the Military Police, the Special Operations Battalion (BOPE). He was accused without proof of hiding guns for the traffickers who were still trafficking and showing provocatively their guns inside the "pacified" favela. Because his corpse never appeared, various protests included the poster: "Where is Amarildo?" This was a turning point for the UPPs since the police image was very much damaged. The project today is more unstable and it is necessary to think if and how it can follow the initial precepts and philosophy with which it gained the approval of the majority of city dwellers, including favelados, saving lives and bringing them hope.

Furthermore, several clashes with armed drug dealers killed dozens of policemen, increasing even more the tension, the fear, and the stress of working inside the favelas. Young favela dwellers also died from gun fire, some of them accused of being part of drug gangs that the dwellers almost always declared innocent, others dying from what police identify as "stray bullets". As a result, a new social movement appeared congregating the mothers of these dead youngsters and the ones sent to the youth justice system in which some were supposedly tortured or beaten. This movement has received increasing attention from the national and international press. Mothers are not fooled by "state lies" or silenced.

Actually, the stories are quite different in each favela or community. And their specific history in building associations and in developing drug traffic as well as the local UPP style of handling local affairs are the keys for understanding the open conflicts or the cooperation between policemen and dwellers. Since favelas do not have the same history, since the commander style varies, since practices of officers and 
soldiers in UPPs are not homogeneous, one cannot generalize how residents evaluate and accept this new policing inside favelas.

In certain favelas, dwellers' associations, NGOs, and schools of samba successfully mediated the relations between UPP commander and dwellers. Some commanders uphold the project and are able to make rank-and-file members follow the rules and values of pacification and proximity. But there were several cases of failure, out of which came denunciations of abusive use of force, corruption, and other violations of dweller rights, followed by replacements of the commanders. Residents are not fooled by "state lies" or silenced.

During our research in 2012 and 2013, we interviewed various UPPs in diverse areas of the city that expressed very different views of the project, of proximity and of pacification. Some of them revealed unfamiliarity or low compliance to the precepts of proximity policing, but one defined it as such:

"When we talk about police, I remember that the term comes from the Greek: politia - in company of the town - the police is to preserve the city. Preserve the physical integrity; preserve the assets of this city, of this community. When the community is close to the police, it is integrated in order to solve its security problems; this is "proximity or community policing" developing together the issues that will benefit the community. What we want is that the residents participate in our activities, including our planning."

Therefore, slum dwellers, instead of just suffering, complain when respectful 
commanders are replaced and call for the urgent removal of authoritarian and corrupt ones. Commanders' practices and ideas are not the same for there is no uniformity in their training and management of police units, probably by internal conflicts and serious problems within the Military Police organization, the institution responsible for coordinating the UPPs.

The first attempts at making policemen and dwellers close to each other were sports and music lessons given by policemen. But soon there were complaints that the place of policemen was not in the socio-educational programs for young people because they tended to apply the hierarchical rules and current military discipline while teaching youngsters and children. Dwellers defined such tries as drills and not youth education. In some favelas, these projects have existed since 2000, such as Olympic Villas built in poor areas as a preparation for the Pan-American Games of 2007, and as a project for preventing violence amongst youths In others, such as Cidade de Deus, there were prior projects led by residents who voluntarily taught sports and music or theatre to children and youths for more than 40 years. These attempts stopped.

When evaluating the UPP project, one must avoid the false consensus created out of a conflict situation, that is, by the forced merger of a dissident voice through the official and armed voice. This is especially clear in the relationship between the new UPP military policemen and part of the youth who rebels against their presence but are not silent about it. New tensions have arisen because policemen understand their mission also to enforce order or the laws of the country, arresting criminals on site. As another commander said:

"What we want to do is different: that everyone knows that has to
behave properly, with the motorcycle documents, using helmet, the RASILIANA- Journal for Brazilian Studies. Vol. 4, n.2 (2016). ISSN 2245-4373. 
vehicle up to date, driving license in the pocket. You cannot do anything wrong. You cannot have a very loud sound so as not to bother the neighbors, you cannot commit crime, and you cannot assault a woman. Everyone knows all this, and also knows that the policemen are present: if you do any irregularity, they are able to arrest you. Then the community begins to realize what works, that the law is being fulfilled. Beforehand, in favelas dominated by traffic, it was not possible to hold a marginal that was trafficking in a given locality, a marginal that had killed a person who just came to buy a small cocaine bag. The dealer was there, didn't like the guy, killed him and ran away. How to arrest this marginal? How to get on the hill with hundred-odd rifles, armored car etc.? Not anymore, now we know that so and so killed someone, and the investigation will flow better, the operations will flow better so that policemen can hold a murderer who killed a person who was there just to buy a small cocaine sac."

The second challenge facing the UPP project implementation concerns the social context of the favelas. A survey in 20 pacified favelas of Rio created by the Institute for Work and Society Studies (IETS) shows that $93 \%$ of the favela entrepreneurs are selfemployed. They are small businessmen working alone as tour guides, auto mechanics, pubs owners, post offices informal representatives, and even Internet providers. The survey found an average monthly income for them of $\mathrm{R} \$ 1$ 1,137.29. In Morro dos Prazeres, it drops to $R \$ 737.94$, half of $R \$ 1,435.52$, found in Chapéu Mangueira, a favela in the richest zone of the city. Chapéu Mangueira is surrounded by higher-income neighborhoods, while Morro dos Prazeres is embedded in a complex of favelas in a low- 
income neighborhood. The average monthly wage of Brazilian workers is $R \$ 1,345$, according to the 2010 Census. Entrepreneurship, much criticized by those who see it as a capitalist scheme, has helped families to find a source of income more stable than informal work or chores. Among the entrepreneurs, women dominate: 53\%.

During the Youth Census in ten UPPs, created in late 2013 by Pereira Passos Institute (IPP), 5,400 young people between 14 and 24 years old were interviewed. Of these, surprisingly almost $40 \%$ said they had no religion, 30\% were Catholic and $27 \%$ Evangelical. Almost $90 \%$ of them said they had access to the Internet, $73 \%$ of which every day, almost 70\% having access from home and 5\% from lan houses or Internet cafes. Thus, these youngsters seem to be inserted in post modernity and able to make use of new ways of communicating with the wide world. However, $20 \%$ do not study or work or seek job, i.e. become aspirants for using illegal drugs and, worse, for being involved in crimes. Schooling is still a major unresolved issue, what certainly affects the success of UPP policy: $36 \%$ did not complete high school and only $3.6 \%$ finished university.

Therefore, residents do not support the UPP project unanimously. But they all agree that police action alone is not the solution for violence. Some point to missed socioeconomic demands, others to social practices that have developed in the context of a relative isolation from the political and social life of the city, which we might call the "ghetto mentality" or a conception of a parochial space. They want to be part of the city with liberation from the federal laws or the urban postures of Rio de Janeiro. They want the benefits of urbanization without losing the advantages afforded by the informal economy that allows them to receive light, water, and cable TV signal paying next to nothing. But there is much difference between favelas previously dominated by militias and drug dealers who "sold" such services through the mediation of neighborhood 
associations, as well as the fees charged on all real estate transactions that occur without records in registry offices, only documents from the dwellers' association that have no legal status outside the favela. A ghetto mentality is the result of making the favela a unique social order, closed in itself, outside the city, with its own "laws", refusing those of the urban world of which it wants to be part of. The urban and legal development of favelas is even presented by certain political groups as a betrayal of the "proletarian anti-formal-city" character of favelas.

Some dwellers refer to favelas as "places of mishmash and disorder" that "should be exempted from rules", that justify a resistance to the new order, with routinely present police imposing limits to funk dances and noisy parties in local inns or on floor slabs at the top of houses. Others want and accept the proximity to the police, and emphasized the need for a new community ordination. Not surprisingly, young people sustain more the first ideas, whereas adults and the elderly, the latter.

"I think there was a very good change, because earlier the children could not get to the street; lots of bandits were up and down the streets with their motorcycles, did not let the children play. We were afraid to let our children walk in the streets, we were afraid to let our children go to school because they had to go through where they were. So today we have no fear, we have a much better sense of security. Today I see how it helps, at least for me, I, a resident, I see this as an improvement like water into wine. The UPP police are well present, no matter the day or the hour, at dawn with sun or rain, we're always seeing the police around our house, where we lived on the main street, and I never hear a sound of shooting, no one screaming, fighting. None of it, because 
everything is being directed to the authority, and the real authority that is the power of the State, the State is doing this with its police inside the community. For me it is very important, and I hope they have come to the community to stay. I hope they do not come out anymore, that really pursue this state government's plan, and that they remain for a long time. We have been already here in the community unable to go home because the bandits did not allow us to pass, and now nothing of the kind happens, you can go in and out. Formerly the taxi driver did not want to leave us at the door of our house. Because formerly the offender aimed that people imagine the police as the enemy, then the state turned out to be the enemy. Every time someone was hit, the traffickers would close the route, put fire in cars and buses, it was wrong. Because the State did not act in the place where it should be the State's domain. I hope that the community will have more courses, more activities, that we can pass by a police officer and say, as I do: good morning, good afternoon, good evening. Some people are still afraid to speak, they are still oppressed. I do not, thank to God. He is here representing the state; the state is one of us. Instead of being repressed by so-and-so, you know that the state is present... But I hope they have more activities with us, they become closer to us for not having that atmosphere of oppression, of looking at the policeman and thinking: My God, what will it happen?"

There is a clear generational conflict as well as an effect of a quite widespread fear that traffickers will return if the UPP project fails or the new government elected in 2014 
cancels it. There is also a tension, perhaps the most important though not the most evident, between the private, parochial and public spheres, the greatest of which turns around what would be the "public order". There is a great diversity of meanings attributed to the new police presence and several contradictory positions linked to what are the individual private freedom and the collective public spaces that should be ruled according to current urban postures.

The issue is not about an attempt to regulate the local everyday life according to strongly invasive patterns of the residents' privacy. Indeed, among them, there are various positions and divergent interests relative to the noise produced by parties and balls. The actual manifestation of civil rights is the demand that the rules and the time allowed for using public space should be discussed by the policemen and the locals.

Another problem concerns what they call "esculacho" or the usual treatment of favela dwellers by the police: the invasion of households, the kicking doors by jackbooted policemen, or the checking of students' bags for drugs and weapons. The first, just after occupation, is practiced less and less by the military forces, but the second became the main reason for conflicts between the police and youths of both sexes, particularly young males. This is now an important demand referred to individual rights, concerning privacy and civil rights. Because confrontations between policemen and drug dealers restarted in mid-2013, policemen kept the old practice of daily stopping youngsters to search them, leaving them humiliated and revolted. Once again young people are the ones who criticize the police presence by violating what they consider as the respect due to them. But almost all residents are aware of "esculacho" and deplore it.

Dwellers are also differently connected to the former "owners of the hill", some closely related or identified to the traffickers, some profiting from their presence inside 
the favela, some just having the loose relations as neighbors or kin that have always existed. The equation is complex because locals never uphold a unanimous acceptance of the traffickers' armed presence and control.

Though traffickers have not destroyed fully the community life in the dominated favelas, they have killed many independent community leaders and disorganized local associations. Their armed and watchful presence, classifying the surrounding favelas as friend or enemy, limited access to relatives, friends or mere visitors from other areas of the city. Local politicians, government officials, and residents from the beginning said that the UPP recovered the residents right to come and go, which was extended to outsiders and city tourists. Thus, local associations and businesses started to rely on the presence of increasingly frequent visitors who did not come just to buy illegal drugs. According to the newspaper O Globo of May 19, 2013, the cable car that serves the favelas in the Complex of Alemão received then 12,000 passengers per day, and on weekends $60 \%$ of the public would not be locals but visitors, which would indicate a greater number of visitors there than in other traditional sights of the city of Rio de Janeiro. ${ }^{4}$

Other new problems have emerged, such as the risk of gentrification and the accusation that the favela was being overrun by outsiders or foreigners, as happened in the Vidigal favela that has the most beautiful view of the city, very close to the wealthy South Zone, where foreigners have been moving to live, rent or even buy "properties".

In the favelas with UPPs, there was not only a reconfiguration of power relations, but also new leaders emerging and replacing old ones, who were submitted to the control of traffickers. There were also changes in the local economy with a flourishing of

4 Accessible at: http://oglobo.globo.com/rio/teleferico-do-alemao-bate-icones-do-rio-em-numero-de-visitantes8433461

3RASILIANA- Journal for Brazilian Studies. Vol. 4, n.2 (2016). ISSN 2245-4373.

(C) $\mathbb{Q} \Theta \Theta$ 
new trades, new informal real estate transactions, and new productive organizations such as cooperatives of handmade products.

Not even favela traders are unanimous about the UPP project. Among those heard by researchers from NUPEVI, ${ }^{5}$ many have shown great relief with the end of relentless shootings that "harmed the community", but especially harmed them, who were coerced to provide food, money or drinks to some drug dealers and their soldiers. Among the new problems now arising are the same complaints that plague small business owners or self-employed workers in the formal city: high taxes, unfair competition of unregulated products or itinerant trade, and irregular inspection.

But there are merchants negatively affected by the UPP occupation, because they were the privileged suppliers to the parties and funk balls promoted by traffickers, obtaining profits from the presence, on these occasions, of drug users who were regulars in these dances and widely consumed illegal drugs, food, and other beverages.

Since clashes between traffickers' factions, and orders for closing shops and schools have been resumed in the larger centers of illegal drug trade, such as the complexes of Rocinha and Alemão, shootings with policemen restarted as well. Without the support of the Federal and Civil Police intelligence sector, the Military Police had to strengthen patrols after the attacks, returning to old practices of "bandit hunt". The difficulty in fighting crime in pacified areas is also due to the lack of strategic planning of the intelligence sector. To make matters worse, there is corruption, lack of transparency in actions, and disputes between policemen.

In our visits to the constructions made by the Federal Housing Project (PAC), we could observe some mismatch between the original plan and the actual uses by the residents. The idea of a condominium in which all residents are responsible for certain

\footnotetext{
${ }^{5}$ Rodrigo de Araújo Monteiro and Ana Cristina Abreu were the interviewers and observers from 2010 to 2014. 
costs and to maintain it clean is still absent. Problems have grown from the way popular housing were built and distributed, the low democratization of public spaces and a gap between institutions responsible for preparing the most vulnerable young people to become workers, entrepreneurs and citizens.

One must also consider the links dwellers and the political power of representatives in the legislature and, through them or directly, to the executive power of the city or the state. Such connections, through go-betweens or through local voluntary associations and NGOs, are part of the picture one wants to understand. These local power settings may or may not promote, encourage or block the ability of neighbors to organize themselves for solving common problems. Youth socialization would be one of them, always linked, according to ethnographic data, with the local existence of elementary and high schools as well as professional courses. In some of the less politicized favelas, the practice of patronage via canvassers mediates the relationship of residents with government, making it difficult to build the social networks necessary for the participation of neighbors in the solutions to meet the common good.

There are reports that highly placed police officers in UPPs have been sought out by residents to solve small everyday problems (that are part of the daily activity of any police institution, but do not compose its core function), and to act as mediators in accessing other public institutions and services. Even at an early stage, one can see that UPP officers begin to play the role of political and administrative mediators that formerly was played by neighborhood associations. It is early to say whether the latter have lost strength and legitimacy, both internally and externally, versus the armed power of traffickers and militiamen and whether they can today convey some level of autonomy in face of the UPP commander's power. 
Yes, it is necessary to respect the freedom and dignity of youths, as well as of adult neighbors that are dealing for a long time with the most vulnerable, trying to prepare them to acquire the "personality capital", as well as social capital or the network of social relations that will make them able to overcome the challenges and obstacles placed to them for becoming responsible adults participating in local social life. And one should recognize that, all over Brazil, disadvantaged youngsters have increased their schooling, are now more familiar with new communication technologies, and may become ready to participate in the country political life. It will depend on how they will be received by different methods of action, if violent or destructive, if by talking about what is considered wrong, dangerous or unlawful.

The growth of mugging on the streets after the UPP installation clearly points to a deficiency of the security policy that should bring together various government agencies, not just the Military Police. There was a lack, as already suggested, of investment in socializing programs to prevent violence and crime that ultimately kill them so soon, teaching civic and nonviolent coexistence. At school, it is necessary to talk openly about the use of psychoactive drugs and their effects, even inviting users to tell their experiences and what they had to face when use became abusive. It is necessary to discuss and expose the problems resulting from lure of money and power gained from the guns obtained with traffickers, including calling former dealers to talk about the high price paid by those who entered into what many of them call "illusion." As explained to me by a former drug dealer, much aware of what is going on:

"So the child who is eight, nine years old, leaves school every day, gets home, change clothes, go to the street to play, and see all that is there. In a moment, he is 12,13 years and begins to feel the needs, wanting 
clothes or sneakers, and her mother cannot afford to give him. Then he starts to talk "when I grow up I'll be the guy." In a little while, he drops out of school, leans at the retail outlet, starts at the lookout corner warning the approach of policemen with fireworks, until he finishes carrying a weapon. So, if the government invested, he would study, he would be training sports, be occupied. If he had at least one apprentice salary, he would not have time to be there all day looking at that banditry. He would have his money. Then, this would weaken the traffic. Over the following years, soldiers would lack, because soldiers are like wind, when one is killed another comes. But if there were brakes for those outside, they would not get there. Those already trafficking would die or go to jail and, over the years, soldiers for the traffic would lack. Then it would work."

\section{References:}

Clifford, J. The Predicament of Culture. Cambridge e London: Harvard University Press, 1988.

Das, Veena. "The Signature of the State: The paradox of legibility". In: das, V. and poole, D. Anthropology in the Margins of the State. New Mexico: School of American Research Press, 2004.

Sampson, Robert J.; Morenoff, Jeffrey D. and Gannon-Rowley, Thomas. "Assessing neighborhood effects: Social Processes and New Directions in Research". In: Annual Reviews Sociology, 28: 443-78, 2002. 
Stewart, Ch. \& shaw, R. Syncretism and Anti-Syncretism. London and New York: Routledge, 1994.

Taussig, Michael T. Shamanism, colonialism, and the wild man: a study in terror and healing. Chicago, London: University of Chicago Press. 1987

Turner, Jonathan H. On the Origins of Human Emotion. Stanford: Stanford University Press. 2000.

Zaluar, Alba \& monteiro, Mario Francisco G. "Desigualdades regionais do risco de mortalidade de jovens: Raça, renda e/ou escolaridade da mãe?" In: Dilemas: Revista de Estudos de Conflito e Controle Social , -5-3 pg 369-386, 2012

\& Ribeiro, Ana Paula A.G. 2009. "Teoria da eficácia coletiva e violência: o paradoxo do subúrbio carioca". Novos Estudos CEBRAP, 84: 175-199. Available at: http://dx.doi.org/10.1590/S0101-330020090002000102009

. Integração Perversa, Rio de Janeiro: Editora FGV, 2004.

. "Democratização Inacabada: fracasso da segurança pública", em Estudos Avançados 21 (61), 2007. 